\title{
ÂMBITO DE ATUAÇÃO DA JUSTIÇA ELEITORAL NA HIPÓTESE DE DIVULGAÇÃO DE FAKE NEWS POR MEIO DAS REDES SOCIAIS
}

\author{
The role of electoral justice in fake news disclosure on social media
}

\author{
Eduardo de Carvalho Rêgo \\ Luiza Cesar Portella
}

Resumo: Partindo da premissa de que a integridade eleitoral deve ser abordada enquanto valor constitucional a ser resguardado no processo eleitoral brasileiro, e de que os meios de comunicação possuem papel pré-definido no processo eleitoral pátrio, o presente artigo científico tem por objetivo identificar o âmbito de atuação da Justiça Eleitoral na hipótese de divulgação de fake news por meio das redes sociais. Vale dizer: diante da constatação de divulgação de notícias falsas pelas redes sociais, e tendo essas notícias falsas o potencial de influenciar o resultado final do pleito eleitoral, quais instrumentos estariam à disposição da Justiça Eleitoral para a correção das distorções verificadas? O método de abordagem utilizado será o indutivo, no qual as análises das características dos fenômenos particulares servirão de base a conclusões de caráter genérico.

Palavras-chave: Integridade eleitoral. Redes sociais. Fake news.

\begin{abstract}
Based on the premise that electoral integrity must be approached as a constitutional value to be safeguarded in the Brazilian electoral process, and that the media have a pre-defined role in the national electoral process, this paper aims to identify the scope of Brazilian Electoral Justice's action in the event of disclosure of fake news through social media. In other words, given the fact that fake news has been disseminated through social media, and if such fake news has the potential to influence the result of the election, what instruments would be available to the Brazilian Electoral Justice to correct the distortions? The scientific method of approach will be the inductive, in which the analysis of the characteristics of the phenomena will be the basis for conclusions of a generic character.
\end{abstract}

Keywords: Electoral integrity. Social media. Fake news. 


\section{Introdução}

O surgimento das primeiras redes sociais, em meados da década de 1990, foi permeado pela intenção de conectar e facilitar a comunicação entre as pessoas, via internet, num mundo que já se apresentava robustamente globalizado. Na origem, as redes sociais tinham por objetivo principal a veiculação de conteúdos pessoais e a interação de pessoas com interesses comuns ${ }^{1}$.

Com o passar do tempo, essas redes ampliaram sensivelmente o seu escopo e, hoje, praticamente não há âmbito da vida que não esteja nelas presente. Por exemplo, é possível gerenciar pelas redes sociais as mais diversas relações provenientes dos âmbitos familiar, profissional, comercial e, de igual maneira, as relações provenientes do âmbito político.

O tema "redes sociais" e "eleições" tem ocupado a Justiça Eleitoral brasileira (ao menos o Tribunal Superior Eleitoral) desde as eleições de 2008, pleito no qual pré-candidatos e partidos políticos foram condenados e sancionados pela realização de propaganda eleitoral extemporânea via orkut, uma vez que a antecipação de propaganda eleitoral é vedada pela legislação ${ }^{2}$.

Nas eleições de 2010, o Tribunal Superior Eleitoral teve de lidar com a popularização do twitter, rede social criada com o objetivo de conectar os usuários, por meio da divulgação, em seus perfis, de mensagens e informações curtas (na época, com até 140 caracteres). Por ocasião do julgamento do Recurso Especial Eleitoral n 7464, de Natal/RN, o TSE decidiu que, por configurar "conversa entre pessoas", o twitter não poderia ser considerado um veículo de divulgação de propaganda eleitoral antecipada, sob pena de indevida "restrição às liberdades de pensamento e expressão"3.

Desde então, o uso das redes sociais nos pleitos eleitorais cresceu bastante. Tanto assim, que diversos analistas atribuem a vitória de Jair Bol-

\footnotetext{
${ }^{1}$ DAQUINO, Fernando. A história das redes sociais: como tudo começou. Disponível em: www.tecmundo.com.br/redes-sociais/33036-a-historia-das-redes-sociais-como-tudo-comecou.htm. Acesso em: 03 set. 2019.

${ }^{2}$ Cf. TSE, Agravos Regimentais em Agravo de Instrumento n ${ }^{\circ} 10.104$ e n ${ }^{\circ}$ 10.105, ambos de Serra Negra/SP. Relator: Min. Arnaldo Versiani. Data: 19 ago. 2010.

${ }^{3}$ Cf. TSE, Recurso Especial Eleitoral no 7464 , de Natal/RN. Relator: Min. Dias Toffoli. Data: 12 set. 2013.
} 
sonaro nas últimas eleições gerais, ocorridas em 2018, à força do referido candidato em redes sociais como o facebook, o twitter, e o whatsapp ${ }^{4}$.

Ocorre que a popularização das redes sociais, e a sua consequen- te influência no resultado do pleito de 2018, trouxe consigo não apenas a aproximação entre os candidatos e os eleitores, mas também migrou para a seara eleitoral, prática já difundida há alguns anos nas mais diversas redes sociais espalhadas pela internet: a divulgação das chamadas fake news.

Podendo ser traduzidas para o português como "notícias falsas", fake news nada mais são do que informações inverídicas - ou, simplesmente, mentiras - divulgadas, normalmente via internet, frequentemente por usuários de redes sociais, como se fossem verdadeiras. A grande questão é que, embora os criadores das fake news ajam de má-fé, os "compartilhadores" de tais mentiras muitas vezes não atuam com dolo, uma vez que, quase sempre, também são vítimas das notícias falsas. Isto é: quem compartilha fake news, muitas vezes acredita que está compartilhando uma notícia verdadeira.

Tendo identificado o alto poder lesivo das fake news ao longo da corrida eleitoral de 2018, inclusive para o cargo de Presidente da República, o Tribunal Superior Eleitoral chegou a lançar página na internet, com "esclarecimentos sobre informações falsas veiculadas nas eleições 2018". Na mesma época, o então Presidente do TSE, Ministro Luiz Fux, concedeu uma série de entrevistas, declarando que as eleições poderiam até mesmo ser anuladas por causa de tais notícias fraudulentas ${ }^{6}$.

Diante desse cenário é que o presente texto busca analisar o âmbito de atuação da Justiça Eleitoral na hipótese de divulgação de fake news pelas redes sociais. Ou seja, o que se pretende é: diante da constatação de divulgação de notícias falsas pelas redes sociais, e tendo essas notícias falsas o potencial de influenciar no resultado final do pleito eleitoral, quais instrumentos estariam à disposição da Justiça Eleitoral para a correção das distorções verificadas?

\footnotetext{
${ }^{4}$ DIAS, Marina. Papel das redes sociais na eleição de Bolsonaro é tema de debate nos EUA. Disponível em: www1.folha.uol.com.br/poder/2019/04/papel-das-redes-sociais-na-eleicao-de-bolsonaro-e-tema-de-debate-nos-eua.shtml. Acesso em: 03 set. 2019.

${ }^{5}$ TRIBUNAL SUPERIOR ELEITORAL. Fake News: TSE lança página para esclarecer eleitores. Disponível em: www.tse.jus.br/imprensa/noticias-tse/2018/Outubro/fake-news-tse-lanca-pagina-para-esclarecer-eleitores-sobre-a-verdade/view. Acesso em: 07 set. 2019.

${ }^{6}$ LELLIS, Leonardo. Luiz Fux: Eleições podem até ser anuladas por causa de 'fake news'. Disponível em: veja.abril.com.br/brasil/luiz-fux-eleicoes-podem-ser-anuladas-por-causa-de-fake-news. Acesso em: 03 set. 2019.
} 
Para tanto, procurar-se-á abordar, através do método indutivo ${ }^{7}$, a integridade eleitoral enquanto valor constitucional a ser resguardado ao longo de todo o processo eleitoral brasileiro, bem como o papel dos meios de comunicação no processo eleitoral à luz do ordenamento jurídico pátrio.

\section{Integridade eleitoral enquanto valor constitucional a ser resguardado no processo eleitoral brasileiro}

O combate à prática de ilícitos eleitorais (direito sancionador eleitoral) encontra lastro na própria Constituição Federal quando assenta o princípio da soberania popular na garantia do exercício do "sufrágio universal e pelo voto direto e secreto, com valor igual para todos" (art. 14, caput, da $\mathrm{CF} / 88$ ).

A garantia da integridade eleitoral não se perfaz somente através de sua feição "formal" (a regularidade formal do processo de sufrágio sem fraudes no escrutínio); a própria Constituição exige que o Estado garanta "a normalidade e a legitimidade das eleições contra a influência do poder econômico" (art. 14, § 9, da CF/88), autorizando inclusive que os mandatos populares sejam desconstituídos se houver a comprovação da prática de abuso de poder econômico, corrupção e fraude" (art. 14, § 10, da CF/88).

Certa concepção de integridade eleitoral foi abordada recentemente pelo Supremo Tribunal Federal. Seu contexto pode ser mais bem compreendido a partir da leitura de trechos dos votos vencedores proferidos nos autos das ações declaratórias de constitucionalidade $n^{\circ} 29$ e 30, que julgaram a Lei Complementar n 135/2010, a chamada "Lei da Ficha Limpa”, compatível com a Constituição Federal de 1988.

Um dos mais emblemáticos votos nesse sentido é o do Ministro Carlos Ayres Britto. Em sua manifestação, o então Ministro não só a declarou constitucional, como também elogiou a Lei da Ficha Limpa. Segundo

\footnotetext{
${ }^{7}$ Ainda que do ponto de vista lógico-formal o método de abordagem escolhido seja o indutivo, é preciso, contudo, não ignorar que, como salienta Silvio Luiz de Oliveira, "a dedução e a indução, tal como síntese e análise, generalizações e abstrações, não são métodos isolados de raciocínio e pesquisa. Eles se completam na realidade e só são separados para efeito de estudo e facilidade didáticas. A conclusão estabelecida pela indução pode servir de princípio - premissa maior - para a dedução, mas a conclusão da dedução pode tam-bém servir de princípio de indução seguinte - premissa menor -, e assim sucessivamente" (OLIVEIRA, Silvio Luiz de. Tratado de Metodologia Científica. 2. ed. São Paulo: Pioneira, 1999, p. 63).
} 
ele, a referida lei nada mais fez do que dar concretude ao princípio constitucional da moralidade e ao subprincípio da probidade administrativa. Mais ainda: em sua análise, as regras positivadas na Lei da Ficha Limpa, de certo modo, já estariam pressupostas na própria Constituição. Eis o raciocínio:

[...] a Constituição criou uma espécie de devido processo legal eleitoral substantivo, que tem duas vertentes, parece-me, ou dois conteúdos: primeiro, é o princípio da respeitabilidade, aquele que sai do campo da presentação de si mesmo e se desloca para o campo da representação de toda uma coletividade, investindo-se em prerrogativas, como inviolabilidade, que é material, e imunidade, que é processual, e se tornando membro do poder, a face visível do Estado, a encarnação do poder público. Tem que ter respeitabilidade, porque uma coisa é o direito individual a se presentar nos atos da vida civil em geral; outra coisa é o direito político de representar toda uma coletividade. Presentação é uma coisa. Representação é um plus de significação jurídica, a demandar um regime jurídico também muito mais qualificado. Foi o que fez a nossa Constituição.

Agora, ela não esgotou o assunto. Que assunto? A sua focada preocupação de proteger a probidade administrativa e a moralidade para o exercício do mandato. E foi uma preocupação tão focada, tão séria, que mandou considerar a vida pregressa do candidato - a vida pregressa do candidato.

E vida pregressa, volto a dizer, é uma vida biográfica, é um histórico de vida, é toda uma trajetória de vida do candidato que não pode estar imersa numa ambiência de nebulosidade no plano ético, menos ainda numa ambiência, digamos assim - os pilotos de avião temem muito uma nuvem chamada cumulus nimbus, que é capaz de derrubar um avião em pleno voo, evidentemente - uma pessoa que desfila pela passarela quase inteira do Código Penal ou da Lei de Improbidade Administrativa pode-se apresentar como candidato? Candidato vem de cândido, que significa - o étimo da palavra explica bem - cândido é puro, é limpo, é depurado eticamente. E candidatura significa limpeza, pureza ética.

E nós sabemos dos costumes romanos, de os senadores vestirem-se com aquelas túnicas brancas para sinalizar a sua pureza de propósitos de intenções no trato da coisa pública [grifos acrescidos].

A "tese da candura", poeticamente desenvolvida pelo Ministro Carlos Ayres Britto em seu voto, embora escorada em premissa segundo 
a qual não concordamos ${ }^{8}$, sintetiza, pelo menos, uma das facetas por trás da chamada integridade eleitoral: não basta que os pleitos eleitorais sejam legais ou observantes da lei; é necessário que os seus participantes, os candidatos, sejam reconhecidos como legítimos postulantes dos relevantes postos que pretendam ocupar. As ideias de pureza, limpeza e depuração, traduzem bem aquilo que se busca numa eleição: a integridade eleitoral.

O principal reparo que propomos à tese esposada pelo ex-Ministro Carlos Ayres Britto, além da discordância explicitada por meio da nota de rodapé explicativa $n^{\circ} 10$, é que "pureza", "limpeza" e "candura" não devem ser características a pesar apenas sobre a pessoa dos candidatos, mas, sobretudo, são pressupostos que permeiam o processo eleitoral como um todo.

Na verdade, quando se pensa em “integridade eleitoral”, é muito mais relevante focar no processo eleitoral, em si, do que no candidato, pois o potencial lesivo de um pleito distorcido é muito maior do que o impacto da eleição de um candidato "ficha suja". Isso porque, no pleito distorcido, provavelmente o eleitor foi enganado (como, por exemplo, no caso de disseminação de fake news), enquanto que, na eleição bem-sucedida de um candidato "ficha suja", o eleitor provavelmente ponderou a vida pregressa do candidato de maneira menos rígida do que a Justiça Eleitoral.

\section{O papel dos meios de comunicação no processo eleitoral à luz do ordenamento jurídico pátrio}

A propaganda sempre ocupou o seu espaço no campo político. Já na Antiguidade era utilizada para persuadir, influenciar opiniões ou incutir impressões, a fim de provocar nas pessoas o sentimento de empatia ou de rejeição acerca de uma determinada ideia ${ }^{9}$. No jogo eleitoral brasileiro, a realidade não é diversa.

\footnotetext{
${ }^{8}$ Entendemos que a Constituição Federal de 1988 não alberga, explícita ou implicitamente, a tese de que a vida pregressa do candidato deva necessariamente pesar contra ele em sua possível candidatura. Menos ainda quando se pretender alijar um candidato do pleito eleitoral sem que haja uma decisão condenatória transitada em julgado. Nesse sentido, comungamos do entendimento de Ruy Samuel Espíndola, para quem a decisão do STF deixou de considerar o princípio da presunção de inocência, bem como "a regra do artigo 15, III, da Constituição, que garante que a suspensão dos direitos políticos só se dá com o trânsito em julgado da sentença penal condenatória”. (ESPÍNDOLA, Ruy Samuel. Direito Eleitoral: a efetividade dos direitos políticos fundamentais de voto e de candidatura. Florianópolis: Habitus, 2018, p. 28)
}

${ }^{9}$ GOMES. José Jairo. Direito Eleitoral. 12. ed. São Paulo: Atlas, 2016. 
No recente período eleitoral democrático, inaugurado pelas eleições gerais diretas de 1986, a propaganda passou a integrar as eleições. Desde então, os meios de comunicação sofreram profundas mudanças, o que exigiu a adequação das regras jurídicas à realidade social ${ }^{10}$, de modo que a atual redação da Lei Federal n$^{\circ}$ 9.504/1997 dispôs sobre nuances que não poderiam nem sequer ser imaginadas pelo legislador e/ou pelo exegeta quando da promulgação da Lei Federal nº 7.493/1986.

Os meios de comunicação são peça chave no processo eleitoral, pois são o canal para a veiculação das propagandas eleitorais e proporcionam ao cidadão o conhecimento dos candidatos. Não à toa que, dentre os cinco maiores tipos de despesa na eleição de $2018^{11}$, três deles estão relacionados à propaganda eleitoral ${ }^{12}$.

Classicamente, o veículo com maior destaque na difusão de propagandas eleitorais é a televisão, inclusive com cessão do chamado "horário nobre" para a veiculação das propagandas. No novo milênio, entretanto, com a consolidação da internet e de suas respectivas redes sociais, tem-se operado uma revolução no processo eleitoral, uma vez que as redes sociais passaram a ocupar um lugar de destaque ${ }^{13}$. A popularização das redes

\footnotetext{
${ }^{10}$ Desde 1986, a legislação eleitoral foi alterada incontáveis vezes. Excluindo as alterações legislativas da Lei Federal $n^{\circ}$ 9.504/1997 e as resoluções do TSE, contamos ainda com outras 4 leis que estabelecem normas para as eleições, a saber: Lei Federal $\mathrm{n}^{\circ}$ 7.493/1986, Lei Federal $n^{\circ}$ 7.773/1989, Lei Federal n ${ }^{\circ}$ 8.214/1991 e Lei Federal n ${ }^{\circ}$ 9.100/1995.

${ }^{11}$ TRIBUNAL SUPERIOR ELEITORAL. Tipo de despesas. Disponível em: www.tse.jus. br/eleicoes/estatisticas /estatisticas-eleitorais. Acesso em: 07 set. 2019.

${ }^{12} \mathrm{O}$ TSE elaborou estatística sobre as contas de campanha prestadas à justiça eleitoral referentes ao pleito de 2018. O tipo de despesa que mais movimentou recursos financeiros foi "despesas com pessoal", seguida de "publicidade por materiais impressos", "energia elétrica", "eventos de promoção da candidatura" e "produção de programas de rádio, televisão ou vídeo".

${ }^{13}$ A respeito do assunto, José Jairo Gomes afirma: "No campo político-eleitoral, as mudanças também já se fazem sentir. Deter informações relevantes e controlar instrumentos e meios de comunicação sempre significou gozar de importante influência no processo político-decisório. Ao promover a descentralização de tais instrumentos, as novas tecnologias de comunicação subverteram a lógica da velha ordem. Por isso, um debate recorrente na atualidade diz respeito às relações entre a política e o papel social dessas novas tecnologias". E, ainda: "Nesse contexto, preocupa o fato de o controle das grandes redes comunicacionais estar nas mãos de poucos grupos empresariais. Não há dúvida de que as instâncias do poder político-econômico podem se valer desse poderio em seu próprio benefício, para, e. g., influenciar os eleitores em benefício ou prejuízo de determinado candidato. Daí a necessidade de se estabelecer rígido controle nesse setor." (GOMES. José Jairo. Direito Eleitoral. 12. ed. São Paulo: Atlas, 2016, p. 556 e 558)
} 
sociais, pois, acelerou a necessidade dos ajustes legais, principalmente em razão da sua consequente influência no resultado dos pleitos.

Em 2018, além das normas previstas na Lei Federal n ${ }^{\circ}$ 9.504/1997, já com as alterações impostas pela Lei Federal $n^{0} 13.488 / 2017$, a propaganda eleitoral foi regida pelas resoluções publicadas pelo Tribunal Superior Eleitoral: Resolução TSE no 23.551/2017 (propaganda eleitoral e horário eleitoral gratuito); Resolução TSE $n^{0} 23.547 / 2017$ (dispõe sobre representações, reclamações e pedidos de resposta previstos na Lei $\left.n^{0} 9.504 / 1997\right)$; Resolução TSE no 23.592/2018 (plano de mídia - segundo turno - eleições presidenciais); Resolução TSE n 23.590/2018 (plano de mídia - eleições presidenciais), sem contar com os planos de mídia elaborados por cada Tribunal Regional Eleitoral. Todas essas normas estabelecem regras sobre o uso dos meios de comunicação no período eleitoral.

À primeira vista, o volume de normas que regulam a propaganda eleitoral pode parecer exagerado. No entanto, a experiência do último pleito demonstrou que, mais do que nunca, é necessário que o ordenamento jurídico estabeleça as balizas dentro das quais os meios de comunicação serão utilizados no processo eleitoral.

Em tempos em que a propaganda eleitoral segue a (equivocada) lógica da polarização entre "esquerda" e "direita" e lança mão, de forma extremada e abusiva, da política de identidade ${ }^{14}$, em que o debate sobre a

${ }^{14}$ Política de identidade é parte do fenômeno da psicologia social pela qual grupos que se identificam socialmente buscam conquistar, ou manter, a hegemonia, enquanto outros lutam por emancipação, ou ao menos visibilidade. Na campanha de 2018, diversos candidatos adotaram estratégias relacionadas à política de identidade para criar legiões de fãs cujo ponto convergente era o ódio contra certos grupos de pessoas que apresentavam características políticas, sociais, afetivas, e até mesmo raciais diversas das suas, ao invés de se identificarem por suas propostas ou ideias. Essa realidade é lastimável e torna-se ainda pior quando inflamada por notícias falsas e (des)informações mentirosas. (RONSINI, Veneza Mayora; OLIVEIRA, Vanessa de. Política de identidade e mídia. E-compós, [s.l.], v. 10, 1 jan. 1970. Disponível em: www.e-compos.org.br/e-compos/article/view/188/189. Acesso em: 08 set. 2019. ALVES, Cecilia Pescatore. Políticas de identidade e políticas de educação: estudo sobre identidade. Psicologia \& Sociedade, [s.1.], v. 29, 18 dez. 2017. Disponível em: www.scielo.br/scielo.php?pid=S0102-71822017000100414\&script=sci_abstract\&tlng=pt. Acesso em: 08 set. 2019. BODZIAK JUNIOR, Paulo Eduardo. A construção política da identidade: um desafio feminista à distinção entre político e social. Revista da Usp: Cadernos de Filosofia Alemã: crítica e modernidade, São Paulo, v. 19, n. 1, p. 85-104, 1 jun. 2014. Disponível em: www.revistas.usp.br/filosofiaalema/article/ view/85598. Acesso em: 08 set. 2019). 
candura dos candidatos parece ser mais importante que os rumos do país ou que as políticas socioeconômicas que serão adotadas na próxima legislatura, o cuidado normativo com os excessos deve ser igualmente robusto; e o compromisso com a verdade, essencial para garantir a efetiva liberdade de voto dos eleitores.

\section{O crescente fenômeno das fake news e a sua relação com as redes sociais}

Sob o ponto de vista positivo, como visto no item anterior, a propaganda eleitoral ocupa lugar de destaque no processo eleitoral. Entretanto, nos últimos anos, é lá que as chamadas fake news têm sido mais divulgadas. Hoje em dia, a divulgação de notícias não tem sido feita apenas por jornalistas, mas também por todos aqueles que operam as redes sociais.

Nos últimos anos, observou-se o grande potencial que têm as fake news para influenciar os pleitos. Isso porque a escolha do eleitor não decorre exclusivamente de elementos racionais, o que abre espaço para os apelos psicológicos, emotivos, apaixonados e, infelizmente, inverídicos ${ }^{15}$.

Na campanha de 2018 não foi diferente. Inclusive, essa foi uma das conclusões a que chegou a Missão de Observação Eleitoral (MOE), enviada pela Organização dos Estados Americanos (OEA), após observar as eleições gerais de 7 de outubro de 2018 e o segundo turno, de 28 de outubro de 2018:

Um dos mais complexos desafios criados pela campanha eleitoral é a disseminação de notícias falsas, atribuídas a seguidores de diferentes setores políticos, por meio das redes sociais e serviços de mensagens na Internet. Embora este fenômeno já tenha sido visto nos processos eleitorais de outros países, as eleições do Brasil apresentaram novos desafios, tais como a utilização de sistemas criptografados para difusão massiva de desinformação.

Apesar dos esforços feitos no Brasil para combater a desinformação, a Missão notou que a proliferação de informação falsa observada por ocasião das eleições do dia 7 de outubro passado intensificou-se no segundo turno das eleições, alastrando-se para outras plataformas digitais, como o Whatsapp. A natureza desta ferramenta, um serviço

${ }^{15}$ Cf. GOMES. José Jairo. Direito Eleitoral. 12. ed. São Paulo: Atlas, 2016. 
criptografado de mensagens privadas, dificulta o já complexo combate à propagação de notícias falsas ${ }^{16}$.

Não à toa, em 07 de dezembro de 2017, o Tribunal Superior Eleitoral instituiu o Conselho Consultivo sobre Internet e Eleições, cujas atribuições são desenvolver pesquisas e estudos sobre as regras eleitorais e a influência da internet nas eleições, em especial o risco das fake news e o uso de robôs na disseminação das informações; opinar sobre as matérias que lhe sejam submetidas pela Presidência do TSE; e propor ações e metas voltadas ao aperfeiçoamento das normas ${ }^{17}$.

Isso não significa, como já visto, que as notícias falsas tenham surgido com as redes sociais, mas estas, certamente, aumentaram o seu potencial de alcance e, sobretudo, de lesividade. As tecnologias aplicadas nas redes sociais se aliam às paixões exacerbadas dos períodos eleitorais.

Hoje existem sofisticadas ferramentas de manipulação das redes sociais, que desestabilizam os esforços de combate às fake news. A disseminação das notícias falsas pode ser feita através da utilização de bots e de técnicas de inteligência artificial aplicadas à análise das reações da rede, por exemplo. Não bastasse, a utilização de VPNs, com mascaramento do endereço digital (IP - "Internet Protocol”) do usuário, dificulta a identificação da origem das notícias.

Robôs, fake news, junk news, big data, são algumas das ferramentas que podem ser utilizadas na propagação da propaganda eleitoral digital fora das regras e do controle da Justiça Eleitoral. A utilização de forma indevida destas ferramentas são prejudiciais ao sistema democrático de disputas eleitorais porque potencializam a divulgação de perfis tanto verdadeiros dos candidatos quanto falsos dos adversários ${ }^{18}$.

${ }^{16}$ ORGANIZAÇÃO DOS ESTADOS AMERICANOS. Relatório Final: Missão de observação eleitoral, eleições gerais, Brasil. OEA, 2018, p. 17. Disponível em: www.oas.org/documents/por/press/MOE-Brasil-2018-Relatorio-Final-POR.pdf. Acesso em: 07 set. 2019.

${ }^{17}$ TRIBUNAL SUPERIOR ELEITORAL. Conselho Consultivo sobre Internet e Eleições discute impacto das fake news. Disponível em: www.tse.jus.br/imprensa/noticias-tse/2018/Outubro/conselho-consultivo-sobre-internet-e-eleicoes-discute-impacto-das-fake-news. Acesso em: 08 set. 2019.

${ }^{18}$ BLASZAK, José Luís. Propaganda eleitoral: novos tempos, novos desafios. Revista do TRE-RS, Porto Alegre, Ano. 23, nº44, p. 143-166, jun. 2018. Semestral. Disponível em: ava.tre-rs.jus.br/ejers/pluginfile.php/2792/mod_resource/content/1/852_Revista_do_ TRE-RS_-_44.pdf. Acesso em: 08 set. 2019. 
Por outro lado, o engajamento de simpatizantes (por vezes cientes da mentira, mas, na maioria, alheios à prática), que veiculam e "compartilham organicamente" essas mensagens, proliferam as notícias e emprestam a elas aparência de legitimidade. A realidade é agravada quando a divulgação provém dos chamados "formadores de opinião", de "pessoas famosas", que nem sempre são imparciais nas suas opiniões.

As redes sociais, pois, possibilitam a divulgação - de forma ampla, rápida e gratuita - de propaganda eleitoral. Ocorre que, na hipótese de disseminação de fake news, as suas consequências são imensuráveis:

Frisa-se, o poder de fogo destas ferramentas, ou seja, a capacidade delas em disparar uma notícia avassaladora e em um segundo de tempo alcançar milhões de eleitores que possuam uma das plataformas de acesso é fator de desequilíbrio certo numa eleição. Como já dito, são manobras digitais capazes de manipular a marcha eleitoral, ferindo o processo democrático de paridade de armas nas disputas entre candidatos $^{19}$.

Assim, em que pese não ser monopólio das redes sociais, a divulgação de fake news está intimamente ligada a elas. Por outro lado, não cabe condenar as redes sociais por isso, ou mesmo vedá-las no âmbito dos processos eleitorais. Ao contrário, o mais desejável seria que as próprias redes sociais fossem utilizadas como ferramenta de combate à proliferação de fake news.

\section{A Justiça Eleitoral no combate à influência das fake news nos processos eleitorais no Brasil}

Atenta a esse cenário, a Justiça Eleitoral inaugurou uma verdadeira batalha contra as fake news. No âmbito das eleições de 2018, o apoio do Ministro Luiz Fux, do STF e então presidente do TSE, foi indispensável.

No exercício da presidência do órgão de cúpula da Justiça Eleitoral, ele assinou parcerias, concedeu entrevistas e proferiu palestras, com o intuito de minorar os efeitos da divulgação das fake news no processo eleitoral então em curso.

${ }^{19}$ BLASZAK, José Luís. Propaganda eleitoral: novos tempos, novos desafios. Revista do TRE-RS, Porto Alegre, Ano. 23, nº-44, p. 143-166, jun. 2018. Semestral. Disponível em: ava.tre-rs.jus.br/ejers/pluginfile.php/2792/mod_resource/content/1/852_Revista_do_ TRE-RS_-_44.pdf. Acesso em: 08 set. 2019. 
Em 06 de agosto de 2018, o Ministro Fux assinou parceria com a Abratel (Associação Brasileira de Rádio e Televisão) visando ao combate à divulgação de notícias falsas ao longo do período eleitoral ${ }^{20}$. No dia seguinte, 07 de agosto de 2018, proferiu a palestra de abertura no "Seminário Academia da Democracia: Eleições 2018 - Desafios e Perspectivas", exaltando os resultados que a Corte Eleitoral por ele presidida conseguiu no combate às fake news ${ }^{21}$. Finalmente, em 22 de agosto de 2018, durante participação no painel "Sociedade da informação e os desafios da informação", promovido pelo 28ํㅡㄹ Congresso Brasileiro de Radiodifusão, em Brasília, o Ministro Fux afirmou que até mesmo uma candidatura poderia ser anulada, desde que calcada em conteúdo falso ${ }^{22}$.

Mas, se realmente é assim, então quais seriam as ferramentas à disposição da Justiça Eleitoral para o enfretamento da questão das fake news? Como poderia a Justiça Eleitoral combater as notícias falsas que influenciam nas eleições e em que hipóteses seria possível "anular" uma candidatura "calcada" em conteúdo falso?

Pois bem. Como visto, há tempos a Justiça Eleitoral preocupa-se com a disseminação de notícias falsas durante os pleitos eleitorais. No campo jurisdicional, contudo, sua atuação é regida pelo princípio da tipicidade das ações eleitorais e limitada à iniciativa das partes interessadas ${ }^{23}$.

Justamente por reconhecer os riscos à democracia decorrentes do monopólio dos meios de comunicação social (as concessões de rádio e TV e os jornais e revistas impressos), é que a legislação, desde longa data, previu

\footnotetext{
${ }^{20} \mathrm{Cf}$. LONDRES, Mariana. Fux assina parceria com Abratel para combate às fake news. Disponível em: noticias.r7.com/brasil/fux-assina-parceria-com-abratel-para-combate-as-fake-news-26042019. Acesso em: 10 set. 2019.

${ }^{21}$ RODRIGUES, Fabio. Fux fala em resultados possíveis no combate às 'fake news' Disponível em: noticias.r7.com/brasil/fux-fala-em-resultados-possiveis-no-combate-as-fake-news-07082018. Acesso em: 10 set. 2019.

${ }^{22}$ BARBIÉRI, Luiz Felipe. Fux diz que candidaturas podem ser anuladas se 'calcadas' em conteúdo falso. Disponível em: g1.globo.com/politica/eleicoes/2018/noticia/2018/08/22/fux-diz-que-candidaturas-podem-ser-anuladas-se-forem-calcadas-em-conteudo-falso.ghtml. Acesso em: 10 set. 2019.

${ }^{23}$ ALVIM, Frederico Franco; CARVALHO, Volgane Oliveira. Da cruz aos códigos: Novas formas de abuso de poder e os mecanismos de proteção da integridade eleitoral no arquétipo brasileiro. Revista do TRE-RE, Porto Alegre, ano. 23, no 44, p. 167-203, jun. 2018. Semestral. Disponível em: ava.tre-rs.jus.br/ejers/pluginfile.php/2792/mod_resource/content/1/852_Revista_do_TRE-RS_-_44.pdf. Acesso em: 08 set. 2019.
} 
a hipótese de apuração de uso indevido dos meios de comunicação social como uma forma de atuar corretivamente em situações em que a sua captura pelos poderes econômico e político contribuem para o falseamento da realidade.

Dentre as ações cíveis eleitorais previstas no ordenamento jurídico, três podem ser usadas para combater a disseminação de fake news no âmbito da campanha eleitoral ${ }^{24}$ :

- Ação de Investigação Judicial Eleitoral (AIJE) - prevista no artigo 14, § 9º da Constituição Federal e no artigo 22 da Lei Complementar Federal $n^{\circ}$ 64/1990;

- Representação - prevista nos artigos $45, \S 4^{\circ}$ e $\S 5^{\circ}, 53, \S 1^{\circ} \mathrm{e}$ $\S 2^{\circ}$, 57-I e 57-J da Lei Federal ${ }^{\circ}$ 9.504/1997, assim como nos artigos 242 e 243 do Código Eleitoral; e

- Representação com Direito de Resposta - prevista nos artigos 57-D, 58 e 58-A da Lei Federal n ${ }^{\circ}$ 9.504/1997, assim como no artigo 243, § $3^{\circ}$ do Código Eleitoral.

Por meio de tais remédios processuais, a Justiça Eleitoral poderá tomar providências para coibir a influência das fake news nos pleitos eleitorais que já ocorreram e naqueles que ainda estão por vir. A tendência, como se nota na fala do Ministro Luiz Fux, e de todas as providências tomadas pelo Tribunal Superior Eleitoral nos últimos anos, é que o Poder Judiciário radicalize e anule eleições quando ficar demonstrado o impacto das fake news no resultado final das eleições.

\section{Considerações finais}

Alçadas à condição de protagonistas nas últimas eleições, em virtude de seu elevado potencial lesivo, as fake news se tornaram motivo de preocupação para eleitores, candidatos e para a Justiça Eleitoral.

Partindo-se da "tese da candura", desenvolvida pelo então Ministro do Supremo Tribunal Federal, Carlos Ayres Britto, no bojo das ações declaratórias de constitucionalidade no 29 e no 30, mas aplicando-a não somente aos candidatos, como também ao processo eleitoral, em si, tem-se

\footnotetext{
${ }^{24}$ A relação apresentada levou em conta as normas legais atinentes ao conteúdo da propaganda divulgada, não abrangendo medidas fundadas em irregularidades formais das propagandas como, por exemplo, anonimato, uso irregular de impulsionamento de conteúdo ou não observação dos padrões exigidos.
} 
que a integridade eleitoral, de fato, não se compatibiliza com pleitos maculados pela difusão de fake news, sendo plenamente concebível o movimento da Justiça Eleitoral no sentido de combatê-las.

Quando se analisa o ordenamento jurídico pátrio, fica claro o relevante e histórico papel dos meios de comunicação no processo eleitoral. Sem eles (rádio, televisão, jornais, internet), os eleitores dificilmente teriam condições de avaliar e escolher conscientemente os seus candidatos favoritos, o que comprometeria sensivelmente o caráter democrático das eleições brasileiras. Ou seja, os meios de comunicação são instrumento essencial para o exercício da democracia no Brasil.

Entretanto, a prevalecer a influência das fake news nos meios de comunicação, tal instrumento democrático perde consideravelmente a sua força. Ora, de nada adiantaria a existência de tantas previsões legais e suas respectivas regulamentações sobre propaganda eleitoral nos meios de comunicação se tais propagandas fossem recheadas de notícias falsas. Quando se tem em mente que o escopo das propagandas eleitorais é justamente a divulgação de candidatos e de suas respectivas ideias, percebe-se que a difusão de fake news tem o enorme potencial de destruir o próprio pleito eleitoral. É que, no momento em que há contaminação por meio da divulgação de notícias falsas, então o próprio propósito da propaganda eleitoral se perde. No lugar da informação, exsurge a desinformação. No lugar da propaganda, exsurge a leviandade. Tanto assim que, para um candidato, muitas vezes, é melhor que não se divulgue nada sobre ele, do que se divulguem notícias falsas, diante do seu potencial perverso.

Para evitar o exemplo brasileiro, pode-se mencionar que, nas últimas eleições presidenciais ocorridas nos Estados Unidos da América, no ano de 2016, provavelmente a difusão de fake news modificou os rumos das eleições, uma vez que o candidato vencedor tinha pouquíssimas chances de ser eleito antes da divulgação de uma enxurrada de notícias falsas sobre a sua principal adversária ${ }^{25}$.

Nos últimos anos, a Justiça Eleitoral brasileira tem se equipado para o combate às fake news. Nesse sentido, muitos de seus representantes já deram a entender que não hesitariam em anular um pleito eleitoral que fos-

${ }^{25}$ VENTURINI, Lilian. Qual o impacto das fake news sobre o eleitor dos EUA, segundo este estudo. Disponível em: www.nexojornal.com.br/expresso/2018/01/14/ Qual-o-impacto-das-fake-news-sobre-o-eleitor-dos-EUA-segundo-este-estudo.Acesso em: 16 set. 2019. 
se comprovadamente influenciado pela divulgação de notícias falsas contra um ou mais candidatos. O Ministro Luiz Fux, que atualmente não mais figura nos quadros de Ministros do TSE, deu início a um forte movimento de combate judicial às fake news. Resta saber se, com a sua saída da Justiça Eleitoral, a atual composição da mais elevada Corte de Justiça Eleitoral do país dará continuidade à empreitada contra a divulgação de notícias falsas ou se o combate anunciado no ano de 2018 perderá fôlego.

Não se pretendeu adentrar, ao longo do texto, no quão democrático seria um movimento da Justiça Eleitoral no sentido de liderar o combate contra a divulgação de notícias falsas pelas redes sociais. Mas o ponto é que se está diante de uma questão de difícil solução. O que seria pior: o "terceiro turno" das eleições nos tribunais, com discussões sobre o que seria "notícia falsa" e o que seria "notícia verdadeira", ou a prevalência das fake news sobre os fatos, a influenciar no processo eleitoral?

De toda sorte, há que ter muito cuidado na definição do âmbito de atuação da Justiça Eleitoral na hipótese de divulgação de fake news por meio das redes sociais, sob pena de trocar-se o potencial "mau uso" das redes sociais pelo "arbítrio" de um órgão julgador, o que, no fundo, também seria ilegítimo e antidemocrático.

\section{Referências}

ALVES, Cecilia Pescatore. Políticas de Identidade e Políticas de Educação: estudo sobre identidade. Psicologia \& Sociedade, [s.l.], v. 29, 18 dez. 2017. FapUNIFESP (SciELO). http://dx.doi.org/10.1590/ 1807-0310/2017v29172186. Disponível em: <http://www.scielo.br/scielo. php?pid=S0102-71822017000100414\&script=sci_abstract\&tlng=pt $>$. Acesso em: 08 set. 2019.

ALVIM, Frederico Franco; CARVALHO, Volgane Oliveira. Da cruz aos códigos: Novas formas de abuso de poder e os mecanismos de proteção da integridade eleitoral no arquétipo brasileiro. Revista do TRE-RE, Porto Alegre, ano. 23, no 44, p. 167-203, jun. 2018. Semestral. Disponível em: ava.tre-rs. jus.br/ejers/pluginfile.php/2792/mod_resource/contente /1/852_Revista_ do_TRE-RS_-_44.pdf>. Acesso em: 08 set. 2019.

BARBIÉRI, Luiz Felipe. Fux diz que candidaturas podem ser anuladas se 'calcadas' em conteúdo falso. Disponível em: g1.globo.com/politica/ eleicoes/2018/noticia/2018/08/22/fux-diz-que-candidaturas-podem-ser-anuladas-se-forem-calcadas-em-conteudo-falso.ghtml. Acesso em: 10 set. 2019. 
BRASIL. Constituição da República Federativa do Brasil de 1988. Disponível em: <http://www.planalto.gov.br/ccivil_03/constituicao/constituicao.htm>. Acesso em: 08 set. 2019.

. Lei Federal no 4.737, de 15 de julho de 1965. Código Eleitoral.

Disponível em: <http://www.planalto.gov.br/ccivil_03/leis/14737.htm>. Acesso em: 08 set. 2019.

. Lei Federal no 7.493, de 17 de junho de 1986. Disponível em: <http://www.planalto.gov.br/ccivil_03/leis/1980-1988/L7493.htm>. Acesso em: 08 set. 2019.

. Lei Federal no 7.773, de 08 de junho de 1989. Disponível em: <http://www.planalto.gov.br/ccivil_03/leis/17773.htm>. Acesso em: 08 set. 2019.

. Lei Federal no 8.214, de 24 de julho de 1991. Disponível em: <http://www.planalto.gov.br/ccivil_03/leis/18214.htm>. Acesso em: 08 set. 2019.

. Lei Federal no 9.100, de 29 de setembro de 1995. Disponível em: <http://www.planalto.gov.br/ccivil_03/leis/L9100.htm>. Acesso em: 08 set. 2019.

. Lei Federal no 9.504, de 30 de setembro de 1997. Disponível em: <http://www.planalto.gov.br/ccivil_03/leis/L9504.htm>. Acesso em: 08 set. 2019.

. Lei Federal no 13.488, de 06 de outubro de 2017. Disponível em: <http://www.planalto.gov.br/ccivil_03/_Ato2015-2018/2017/Lei/ L13488.htm>. Acesso em: 08 set. 2019.

. Lei Complementar Federal $\mathbf{n}^{0}$ 64, de 18 de maio de 1990. Disponível em: <http://www.planalto.gov.br/ccivil_03/LEIS/LCP/Lcp64. htm>. Acesso em: 08 set. 2019.

BLASZAK, José Luís. Propaganda eleitoral: novos tempos, novos desafios. Revista do TRE-RS, Porto Alegre, Ano. 23, no-44, p. 143-166, jun. 2018. Semestral. Disponível em: ava.tre-rs.jus.br/ejers/pluginfile.php/2792/mod_resource/ content/1/852_Revista_do_TRE-RS_-_44.pdf. Acesso em: 08 set. 2019.

BODZIAK JUNIOR, Paulo Eduardo. A construção política da identidade: um desafio feminista à distinção entre político e social. Revista da Usp: CADERNOS DE FILOSOFIA ALEMÃ: CRÍTICA E MODERNIDADE, São Paulo, v. 19, n. 1, p.85-104, 1 jun. 2014. Semestral. Disponível em: <http://www.revistas.usp.br/filosofiaalema/article/view/85598>. Acesso em: 08 set. 2019. 
DAQUINO, Fernando. A história das redes sociais: como tudo começou. Disponível em: www.tecmundo.com.br/redes-sociais/33036-a-historia-das-redes-sociais-como-tudo-comecou.htm. Acesso em: 03 set. 2019.

DIAS, Marina. Papel das redes sociais na eleição de Bolsonaro é tema de debate nos EUA. Disponível em: www1.folha.uol.com.br/ poder/2019/04/papel-das-redes-sociais-na-eleicao-de-bolsonaro-e-tema-de-debate-nos-eua.shtml. Acesso em 03 set. 2019.

ESPÍNDOLA, Ruy Samuel. Direito Eleitoral: a efetividade dos direitos políticos fundamentais de voto e de candidatura. Florianópolis: Habitus, 2018.

GOMES. José Jairo. Direito Eleitoral. 12. ed. São Paulo: Atlas, 2016.

LELLIS, Leonardo. Luiz Fux: Eleições podem até ser anuladas por causa de 'fake news'. Disponível em: veja.abril.com.br/brasil/luiz-fux-eleicoes-podem-ser-anuladas-por-causa-de-fake-news. Acesso em: 03 set. 2019.

LONDRES, Mariana. Fux assina parceria com Abratel para combate às fake news. Disponível em: noticias.r7.com/brasil/fux-assina-parceria-com-abratel-para-combate-as-fake-news-26042019. Acesso em: 10 set. 2019.

OLIVEIRA, Silvio Luiz de. Tratado de Metodologia Científica. 2. ed. São Paulo: Pioneira, 1999.

ORGANIZAÇÃO DOS ESTADOS AMERICANOS. Relatório Final: Missão de observação eleitoral, eleições gerais, Brasil. OEA, 2018. Disponível em: www.oas.org/documents/por/press/MOE-Brasil-2018-Relatorio-Final-POR.pdf. Acesso em: 07 set. 2019.

RODRIGUES, Fabio. Fux fala em resultados possíveis no combate às 'fake news'. Disponível em: noticias.r7.com/brasil/fux-fala-em-resultados-possiveis-no-combate-as-fake-news-07082018. Acesso em: 10 set. 2019.

RONSINI, Veneza Mayora; OLIVEIRA, Vanessa de. Política de identidade e mídia. E-compós, [s.1.], v. 10, 1 jan. 1970. E-compos. http://dx.doi. org/10.30962/ec.188. Disponível em: <https://www.e-compos.org.br/e-compos/article/view/188/189>. Acesso em: 08 set. 2019.

SUPREMO TRIBUNAL FEDERAL. Ação declaratória de constitucionalidade no 29. Relator Ministro Luiz Fux. Julgado em 16 fev. 2012. DJE 29 jun. 2012.

. Ação declaratória de constitucionalidade n⿳3030. Relator Ministro

Luiz Fux. Julgado em 16 fev. 2012. DJE 29 jun. 2012. 


\section{TRIBUNAL SUPERIOR ELEITORAL. Conselho Consultivo sobre}

Internet e Eleições discute impacto das fake news. Disponível em: www. tse.jus.br/imprensa/noticias-tse/2018/Outubro/conselho-consultivo-sobre-internet-e-eleicoes-discute-impacto-das-fake-news. Acesso em: 08 set. 2019.

. Fake news: TSE lança página para esclarecer eleitores. Disponível em: www.tse.jus.br/imprensa/noticias-tse/2018/Outubro/fake-news-tse-lanca-pagina-para-esclarecer-eleitores-sobre-a-verdade/view. Acesso em: 07 set. 2019.

. Tipo de despesas. Disponível em: www.tse.jus.br/eleicoes/estatisticas /estatisticas-eleitorais. Acesso em: 07 set. 2019.

. Resolução n⿳0 23.551, de 18 de dezembro de 2017. Dispõe sobre propaganda eleitoral, utilização e geração do horário gratuito e condutas ilícitas em campanha eleitoral nas eleições. Disponível em: <http://www.tse.jus. br/legislacao-tse/res/2017/RES235512017.html>. Acesso em: 08 set. 2019.

. Resolução no 23.547, de 18 de dezembro de 2017. Dispõe sobre representações, reclamações e pedidos de resposta previstos na Lei ${ }^{\circ}{ }^{-}$ 9.504/1997 para as eleições. Disponível em: <http://www.tse.jus.br/legislacao-tse/res/2017/RES235472017.html>. Acesso em: 08 set. 2019.

Resolução n⿳0 23.590, de 28 de agosto de 2018. Dispõe sobre o plano de mídia do horário eleitoral gratuito relativo ao cargo de Presidente da República nas eleições de 2018. Disponível em: <http://www.tse.jus.br/legislacao-tse/res/2018/RES235902018.html>. Acesso em: 08 set. 2019.

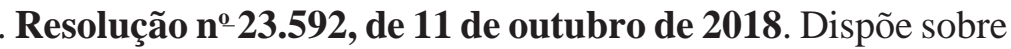
o plano de mídia do horário eleitoral gratuito relativo ao cargo de Presidente da República no segundo turno das Eleições 2018. Disponível em: <http:// www.tse.jus.br/legislacao-tse/res/2018/RES235922018.html>. Acesso em: 08 set. 2019.

Agravo Regimental em Agravo de Instrumento n-10.104. Relator Ministro Arnaldo Versiani. Julgado em 19 ago. 2010. DJE 29 set. 2010.

. Agravo Regimental em Agravo de Instrumento n-10.105. Relator Ministro Arnaldo Versiani. Julgado em 19 ago. 2010. DJE 29 set. 2010.

. Recurso Especial Eleitoral n-7.464. Relator Ministro Dias Toffoli. Julgado em 12 set. 2013. DJE 15 out. 2013, p. 30. 
VENTURINI, Lilian. Qual o impacto das fake news sobre o eleitor dos EUA, segundo este estudo. Disponível em: www.nexojornal.com.br/ expresso/2018/01/14/Qual-o-impacto-das-fake-news-sobre-o-eleitor-dos-EUA-segundo-este-estudo. Acesso em: 16 set. 2019.

Eduardo de Carvalho Rêgo - Doutor em Direito, Política e Sociedade, e Mestre em Te- oria, História e Filosofia do Direito pela Universidade Federal de Santa Catarina (UFSC). Especialista em Direito Constitucional pela Universidade do Sul de Santa Catarina (UNI- SUL). Graduado em Direito pela Universidade do Vale do Itajaí (UNIVALI). E-mail: edu-ardorego@gmail.com.

Luiza Cesar Portella - Especialista em Direito Processual Civil pelo Complexo de EnsinoSuperior de Santa Catarina (CESUSC). Graduada em Direito pela Universidade Federal deSanta Catarina (UFSC) e em Administração Empresarial pela Universidade do Estado de Santa Catarina (UDESC/ESAG). Email: luizaportella@gmail.com 
